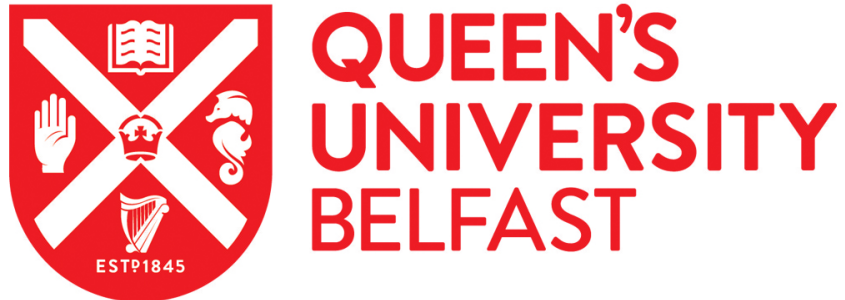

\section{Choosing to engage and choosing to persist: The role of non-specific factors in health-promoting activities}

Gaitan Sierra, C., \& Dempster, M. (2016). Choosing to engage and choosing to persist: The role of non-specific factors in health-promoting activities. British Journal of Health Psychology, 21(3), 515-532.

https://doi.org/10.1111/bjhp.12183

Published in:

British Journal of Health Psychology

Document Version:

Peer reviewed version

Queen's University Belfast - Research Portal:

Link to publication record in Queen's University Belfast Research Portal

\section{Publisher rights}

(C) 2016 The British Psychological Society

This is the peer reviewed version of the following article: Gaitan-Sierra, C. and Dempster, M. (2016), Choosing to engage and choosing to persist: The role of non-specific factors in health-promoting activities. British Journal of Health Psychology, 21: 515-532, which has been published in final form at http://onlinelibrary.wiley.com/doi/10.1111/bjhp.12183/abstract. This article may be used for non-commercial purposes in accordance with Wiley Terms and Conditions for Self-Archiving.

\section{General rights}

Copyright for the publications made accessible via the Queen's University Belfast Research Portal is retained by the author(s) and / or other copyright owners and it is a condition of accessing these publications that users recognise and abide by the legal requirements associated with these rights.

\section{Take down policy}

The Research Portal is Queen's institutional repository that provides access to Queen's research output. Every effort has been made to ensure that content in the Research Portal does not infringe any person's rights, or applicable UK laws. If you discover content in the Research Portal that you believe breaches copyright or violates any law, please contact openaccess@qub.ac.uk. 
Choosing to Engage and Choosing to Persist: The Role of Non-specific Factors in Health-Promoting Activities 


\begin{abstract}
Objective: Non-specific factors play an important role in determining benefits from healthpromoting activities. Research findings suggest that individuals are motivated to engage in activities that they expect to be beneficial, which leads to enhanced beneficial outcomes. Previous studies have focussed on beneficial outcomes of motivation during engagement. We investigated whether motivational factors also influence people's decisions to engage with health-promoting activities in the first instance and then subsequently adhere to them.
\end{abstract} Method: In two studies, participants were informed about a health-promoting activity (Study 1: a breathing exercise for well-being, Study 2: a gratitude exercise for smoking cessation) and told either that it has a "known" or "unknown" effectiveness as a method of influencing their outcome expectancies. Participants were then given the opportunity to engage with the activity over the following days. Participants' intrinsic motivation was also assessed. Results: In both studies, intrinsic motivation positively predicted willingness to engage with the activities as well as subsequent adherence. Describing the gratitude exercise as having a known effectiveness in Study 2 enhanced motivation and adherence to the treatment. Conclusions: Non-specific factors play an important role both in people's willingness to engage with health-promoting activities as well as their subsequent adherence. Our results also show that simple statements about the potential benefits of a health promoting activity can motivate engagement and adherence.

Keywords: expectancies, intrinsic motivation, engagement, adherence. 
Beneficial effects experienced following the course of health-promoting activities can be determined by specific and non-specific factors (e.g., Chiesa, Brambilla \& Serreti, 2010; Crum \& Langer, 2007; Pretty Peacock, Sellens, \& Griffin, 2005). Two psychological mechanisms have been proposed to explain non-specific benefit. Response expectancy theory proposes that benefit is a consequence of positive outcome expectancies (Kirsch, 1985; 1999). Motivational concordance theory (Hyland, Whalley, \& Geraghty, 2007), on the other hand, "is based on the premise that therapeutic treatments have benefit to the extent that the context of the treatment is consistent with and satisfies the client's significant intrinsic goals" (Gaitan-Sierra \& Hyland, 2014 p.259). Motivational concordance theory acknowledges the role that expectancies have as an important component of the cognitive appraisal of treatment outcome. However, according to this theory, it is not only its evaluation but also intrinsic motivation to perform a therapeutic task that can contribute to explain benefit. Thus, effects of expectancies on benefit are mediated by behaviour on the task. Both psychological mechanisms lend support to the idea that the manner in which a treatment context is interpreted and perceived by the individual is crucial for treatment benefit (Moerman \& Jonas, 2002).

The premise that positive engagement with a health-promoting activity enhances benefit has been supported in previous studies of motivational concordance. For example, Gaitan-Sierra \& Hyland (2011) found that when performing a health-promoting breathing exercise, participants who reported exerting more effort also report greater improvements in mood and experienced benefit. Expectancy of benefit also predicted beneficial outcomes, but the effects of expectancies were mediated by effort. Gaitan-Sierra \& Hyland (2013) further found that both effort and intrinsic motivation reported by participants during engagement in a health-promoting non-aerobic exercise predicted greater beneficial outcomes and mediated the relationship between expectancies and outcomes of treatment. 
Motivational factors, namely intrinsic motivation, have also been shown to predict treatment outcomes for real-world therapeutic interventions (Gaitan-Sierra \& Hyland, 2014). These studies have not found a consistent effect of response expectancies on treatment outcome.

Two contextual aspects might explain why expectancy can fail to explain outcome. First, expectancies of benefit have been shown to influence treatment benefit in short-term laboratory tasks, but less so in long-term real-world studies (Hyland, 2011b; Lewith, Hyland, \& Shaw, 2002; Walach et al., 1997). Motivational factors may actually be more important than expectancies of benefit in real-world settings when people are motivated to improve their health. Our current interest is how expectancies motivate engagement with a health-promoting activity that leads to beneficial outcomes. Second, previous studies examining response expectancy and motivational concordance have focussed on engagement during health-promoting activities. Thus, it remains unclear whether expectancy and motivational factors also influence decisions to engage with a health-promoting activity in the first instance, and if so, the degree to which an individual will persist with an activity. The current research tests for effects of expectancy and motivational factors on decisions to engage with a health-promoting activity and subsequently adhere to it.

Motivational concordance theory acknowledges that expectancies of benefit can motivate engagement, which in turn, leads to beneficial treatment outcomes. This suggests that providing information about the potential effectiveness of a health-promoting activity could enhance intrinsic motivation. Indeed, persuasive messages have been shown to motivate people for health change (Kreuter \& Wray, 2003; Martin \& DiMatteo, 2014; Rothman \& Salovey, 1997). Informing people about the potential benefits of health-related activities (e.g., physical exercises that are purported to boost energy and mood) promotes positive health behaviours (Gallagher \& Updegraff, 2012). 
Positive effects of health information can depend also on characteristics of the individual, such as their perceptions of self-efficacy (van't Riet, Ruiter, Werrij, \& DeVries, 2008; 2010). Perceived self-efficacy refers to a belief in one's personal ability to perform a particular activity (Bandura, 1997). The effects of providing information about the potential effectiveness of a treatment may depend on the degree to which the individual feels able to perform a health-promoting activity. Thus, positive health messages may be more persuasive for people who are high in perceived self-efficacy beliefs.

There are two aims in the current research. The first aim is to determine whether response expectancy as a psychological mechanism can explain treatment engagement and adherence to a therapeutic activity. If this is found to be the case, the effects of expectancy on outcome should be direct and not mediated by intrinsic motivation. If motivational concordance is the mechanism explaining outcome, the effects of expectancy should instead be mediated by intrinsic motivation. A test of these psychological mechanisms on outcome will provide a better understanding how they each influence people's decisions to engage with a health-promoting activity and subsequently adhere to it. The second aim is to investigate a method to influence outcome expectancy. Participants were informed about a health-promoting activity and told either that it has a "known" or "unknown" effectiveness. An important aspect of the current research is that participants were then given the opportunity to engage with the health-promoting activity over the following days. We hypothesized that, positive information in the form of the activity having a "known" effectiveness would increase participants' expectancy of benefit and intrinsic motivation, which would in turn determine their choices to engage with the activity and their subsequent adherence to it.

\section{Study 1}

\section{Method}




\section{Participants}

One hundred twenty-one adult US participants ( 68 male, 53 female, mean age $=34$ years, $S D=10.81$ ) were recruited online via Amazon's Mechanical Turk (AMT) in a study purported to investigate the beneficial effects of a breathing method on well-being. Individuals were asked not to participate if they suffered from a respiratory condition that could compromise their ability to safely perform a physical activity. The reliability of the data provided by AMT has been demonstrated through comparisons with other data collection methods (e.g., Berinsky, Huber, \& Lenz, 2012; Paolacci, Chandler, \& Ipeirotis, 2010). The university research ethics committee approved the study and all participants provided informed consent. Participants received a token payment of $\$ 0.50$ for completion of Stage 1, and $\$ 3.00$ for completion of Stage 2 .

\section{Materials and procedure}

\section{Stage 1: Expectations of treatment outcome}

Measures. Perceived self-efficacy in the context of general life events was assessed using the 10-item General Self-efficacy Scale (GSS; Schwarzer \& Jerusalem, 1995; current data, Cronbach's $\alpha=.93$ ).

Breathing method. Next, participants were presented a breathing method vignette, which was based on the Buteyko breathing technique. The Buteyko breathing technique is controversial as there is no general consensus on its effectiveness (Bruton \& Lewith, 2005; Thomas, 2003). For the current purposes, the method was re-labelled the "Lacastre breathing method". Participants were randomly assigned to receive either a "known" effectiveness or an "unknown" effectiveness version of the vignette (see Table 1). On the basis of the vignette, participants rated their expectations about whether the method would improve their well-being on a 7-point scale (1=extremely unlikely, 7=extremely likely). Then participants completed four items to assess their intrinsic motivation to perform the method (e.g., "I 
think the breathing method would be interesting to practice" on a 7-point scale; $1=$ strongly disagree, $7=$ strongly agree; Cronbach's $\alpha=.91$ ). The items were presented in a randomly generated order for each participant. Demographic characteristics of the sample are provided in Table 2.

\section{Stage 2: Engaging with the method}

Choices to engage. Participants were then given the opportunity to practice the breathing method at home over a 5-day period. Participants who agreed to take part in the breathing method received an instruction booklet via email that contained a step-by-step guide on how to perform the "maximum pause" Buteyko breathing method at home. The "maximum pause" method consists of holding the breath after a gentle exhalation, as long as one can, or to the point of moderate discomfort (for a detailed description of the Buteyko breathing method see Novozhilov, 2004). Participants were told to practice the "maximum pause" twice a day, once in the morning and again in the evening, for the following five days.

Experiencing treatment outcomes. On day 6, participants received a web-link via email to complete an online follow-up questionnaire on their experience with the breathing method. Participants reported the benefit experienced when practicing the breathing method on the preceding five days.

Adhering. Participants completed a session diary to identify their adherence to the breathing method. The diary was completed as part of the Stage 2 follow-up questionnaire. Participants were asked to select the sessions (morning and evening) that they completed for each of the five days. In order to encourage them to provide an honest account of their adherence, participants were reassured prior to beginning the follow-up questionnaire that a purpose of the study was to assess their adherence and that their compensation was not contingent on their adherence.

Following completion of the follow-up questionnaire, participants were debriefed and thanked for their contribution.

\section{Results}


Independent $t$-tests confirmed that the "known" and "unknown" effectiveness groups did not differ at baseline in perceived self-efficacy $(p>.100)$.

\section{Expectations of treatment outcome}

Presenting the breathing method as having a "known" effectiveness (as opposed to an "unknown" effectiveness) did not influence intrinsic motivation (independent $t$-test, $\left.\mathrm{M}_{\mathrm{known}}=18.95 ; M_{\mathrm{unknown}}=18.33 ; t(119)=0.76, p=.449\right)$ or expectancy of benefit $\left(M_{\mathrm{known}}=4.70\right.$; $\left.M_{\text {unknown }}=4.30 ; t(119)=1.78, p=.078\right)$.

\section{Factors influencing willingness to engage with the method}

Seventy nine (of $121 ; 65 \%$ ) participants agreed to practice the breathing method over the following five days, but this did not depend on whether the method was purported to have a "known" effectiveness (37/60; 62\%, vs. "unknown" effectiveness, 42/61; 69\%). A logistic regression analysis confirmed no effect of describing the breathing method as having a "known" effectiveness on agreeing to practice the method (Table 3). However, higher intrinsic motivation was associated with a higher likelihood of agreeing to practice the breathing method (Table 3). Expectancy of benefit and perceived self-efficacy were not significant predictors.

\section{Factors in Stage 1 as predictors of adherence}

Of the seventy nine participants who agreed to complete the breathing method, 53 (67\%) returned to complete the follow-up questionnaire. In response to the reported benefit question, no one reported that they felt worse, $39.6 \%$ reported that they felt the same, and $60.4 \%$ that they felt better. With regard to adherence, twenty (38\%) participants reported to complete up to eight sessions, five (4\%) reported completing nine sessions, and a remaining twenty eight $(23 \%)$ reported completing all ten sessions. Hence, adherence was defined as whether or not participants completed all ten sessions. A logistic regression analysis revealed that describing the breathing method as having a "known" effectiveness (as 
opposed to an "unknown" effectiveness) was not associated with adherence (Table 3).

Higher intrinsic motivation was associated with a higher likelihood of adherence (Table 3). Expectancy of benefit and perceived self-efficacy did not predict likelihood of adherence.

\section{Study 2}

In Study 1, presenting a therapeutic breathing method as having a "known" rather than an "unknown" effectiveness did not influence participants' willingness to engage with the method, nor their adherence among those who did engage with the method. One possibility is that participants in Study 1 did not have a strong reason to engage in a therapeutic task. In Study 2, we test for effects of treatment information among individuals who have expressed a desire to stop smoking. Participants were provided with a description of a smoking cessation method based on gratitude therapy that has either a "known" or "unknown" effectiveness. We hypothesized that smokers who receive a vignette about the treatment describing it has having a "known" effectiveness would (a) report more positive treatment expectancies, and (b) would report higher intrinsic motivation to perform the treatment. Subsequently, we further hypothesized that participants provided with the "known" effectiveness vignette would also be more likely to choose to engage in the treatment and show greater adherence to the treatment.

\section{Method}

\section{Participants}

One hundred twenty-one adult US participants (62 men, 59 women, mean age $=36$ years, $S D=12.14$ ) were recruited online via AMT for a study purported to examine the effects of gratitude therapy on smoking cessation. Participants were recruited on the basis that they were smokers who wished to stop smoking, and were not currently undergoing any psychological treatment (e.g., counselling, psychotherapy). The university research ethics 
committee approved the study. Participants received a token payment of $\$ 0.50$ for completion of Stage 1, and $\$ 4.00$ for completion of Stage 2 .

\section{Materials and procedure}

\section{Stage 1: Expectations of treatment outcome}

Measures. Perceived self-efficacy to abstain from smoking was assessed with the sixitem Smoking Abstinence Self-efficacy Questionnaire (SASEQ; Spek et al., 2013; current data Cronbach's $\alpha=.87$ ). Proneness to experience and feeling gratitude in every-day life was assessed with the Gratitude Questionnaire six-item form (GQ-6; McCullough, Emmons, \& Tsang; 2002; current data Cronbach's $\alpha=.91$ ). Willingness to stop smoking was measured with a single item: "How willing are you to stop smoking now?" (from $0=$ not at all willing to stop smoking to $100=$ extremely willing to stop smoking).

Gratitude therapy. Next, participants were randomly assigned to receive one of two versions of the gratitude therapy vignette that described either a "known" or "unknown" effectiveness of the therapy (see Table 4). Following the vignette, participants rated whether they expected that the gratitude therapy would help them to stop smoking (on a seven-point scale ranging $1=$ extremely unlikely to $7=$ extremely likely). Participants then completed four items to assess their intrinsic motivation toward the gratitude therapy (on 7-point scale; Cronbach's $\alpha=.93$ ). The items were presented in a randomly generated order for each participant.

Regarding participants' smoking status, they reported how many cigarettes they smoked per week on average. Table 5 provides the demographic characteristics.

\section{Stage 2: Taking part in the gratitude therapy}

Choices to take part in the therapy. Participants were offered the opportunity to engage with the gratitude therapy at home over a period of 7 days. Participants who agreed to complete the gratitude therapy at home received a booklet, via email, containing 
information on how to perform the gratitude therapy. The therapy included a gratitude diary to be completed on each of the seven days (see Wood, Froh, \& Geraghty, 2010 for other examples of gratitude interventions in health contexts). This task required participants to write down six things they were grateful for on each day.

Experiencing treatment outcomes. On day 8, participants who chose to engage with the treatment received a web-link via email to complete the online follow-up questionnaire on their experience with the therapy. As in Study 1, participants reported the benefit experienced with the therapy on the preceding days, and their current smoking status.

Adhering. As part of the follow-up questionnaire, participants completed a session diary by selecting the days ( 1 to 7 ) that they completed the gratitude diary. Similar instructions were used as in Study 1 to encourage participants to respond truthfully.

\section{Results}

Twenty three participants (19\%) reported being slightly willing to stop smoking, thirty three (27\%) reported being moderately willing to stop smoking, forty seven (39\%) reported being very willing to stop smoking, and 18 (15\%) reported being extremely willing to quit. Independent t-tests comparing the "known" and "unknown" effectiveness groups confirmed no differences at baseline in self-efficacy, gratitude and willingness to stop smoking (all $p s>.100)$.

\section{Expectations of treatment outcome}

As hypothesized, describing the gratitude therapy as having a "known" (as opposed to an "unknown") effectiveness increased intrinsic motivation ( $M=21.19$ vs. $M=18.19$; $t(119)=3.22, p=.002)$ and expectancy of benefit $(\mathrm{M}=4.21$ vs. $\mathrm{M}=3.33 ; t(119)=3.67, p<.001)$. Factors influencing willingness to carry out the gratitude therapy

Sixty seven (of $121 ; 55 \%$ ) participants agreed to practice the gratitude therapy for the following seven days, but this did not appear to depend on whether the gratitude therapy was 
purported to have a "known" $(33 / 58 ; 57 \%)$ or "unknown" $(34 / 63 ; 54 \%)$ effectiveness. A logistic regression analysis confirmed no effect of describing the gratitude therapy as having a "known" effectiveness on choices to engage with the therapy (Table 6). Higher intrinsic motivation was associated with a higher likelihood of agreeing to engage with therapy (Table 6). Expectancy of benefit, perceived self-efficacy, willingness to stop smoking, and gratitude were not significant predictors of choices to engage with the therapy.

\section{Factors in Stage 1 as predictors of adherence}

Of the sixty seven participants who agreed to complete the gratitude therapy at home, $50(74 \%)$ returned to complete the follow-up questionnaire. In response to the reported benefit question, no one reported that they felt worse, $38 \%$ reported that they felt the same, and $62 \%$ that they felt better.With regard to adherence, seventeen (34\%) participants reported to complete up to five sessions, nine (18\%) reported completing six sessions, and a remaining twenty four (48\%) reported completing all seven sessions. A logistic regression analysis on whether or not participants adhered to all seven sessions (among those who completed the follow-up questionnaire) revealed positive effects of describing the therapy as having a "known" effectiveness (Table 6). Higher intrinsic motivation predicted adherence (Table 6). Expectancy of benefit, willingness to stop smoking, self-efficacy, and gratitude were not significant predictors of adherence.

\section{Changes in smoking at follow-up}

A one-way mixed ANOVA was conducted on smoking rate at Stage 1 to Stage 2 for participants who completed the follow-up questionnaire. Whether the therapy was described as having a "known" or "unknown" effectiveness was included as a between-subjects factor. This analysis revealed that smoking rate reduced from Stage $1(M=85.02$ cigarettes per week) to Stage $2\left(M=54.47\right.$ cigarettes per week; $F(1,47)=56.72, p<.001$, partial $\left.\eta^{2}=.547\right)$. Participants who were provided the "known" effectiveness description reported smoking 
fewer cigarettes over the preceding 7 days $(M=53.46$ cigarettes per week, vs. $M=86.04$ cigarettes per week; $F(1,47)=5.53, p=.023$, partial $\left.\eta^{2}=.105\right)$. However, there was not a significant interaction involving stage $\left(F(1,47)=2.21, p=.144\right.$, partial $\left.\mathrm{y}^{2}=.045\right)$, suggesting that while participants who were given the "unknown" description smoked more cigarettes, this was not a result of the manipulation.

\section{Discussion}

In two studies, intrinsic motivation positively predicted people's willingness to engage with a health-promoting activity and subsequent adherence to it. In study 1 , higher intrinsic motivation predicted willingness to engage with a breathing exercise purported to improve well-being. These individuals were also more likely to report adhering to the treatment at follow-up. In study 2, smokers who were high in intrinsic motivation were more likely to engage with a gratitude therapy designed for smoking cessation. High intrinsic motivation was also associated with greater adherence to the treatment. Furthermore, in study 2 , the provision of positive health information about the effectiveness of gratitude therapy for smoking cessation enhanced motivation and adherence to the treatment. The current research suggests that motivational factors play an important role both in people's willingness to engage with health-promoting activities as well as their subsequent adherence to an activity.

Research inspired by motivational concordance theory has shown that motivational factors such as intrinsic motivation are important for therapeutic outcome (e.g., reported benefit, mood change; Gaitan-Sierra \& Hyland, 2011, 2013, 2014). However, previous studies of motivational concordance have focussed on engagement during health-promoting activities. It remained unclear whether motivational factors would also influence decisions to engage with a health-promoting activity in the first instance, and subsequently influence adherence. In the current research, participants were given the opportunity to engage in a 
health-promoting activity after receiving treatment information. In both studies, higher intrinsic motivation predicted a higher likelihood of choosing to engage with a healthpromoting and subsequent adherence.

According to motivational concordance theory and response expectancy theory, anticipated treatment outcome mobilises motivated behaviour, such that greater outcome expectancies can predict higher intrinsic motivation. However, this was not shown to be the case in the current studies. In both studies, outcome expectancies were unrelated to choices to engage with a health-promoting activity as well as subsequent adherence.

Expectancies of benefit have been shown to influence treatment benefit in short-term laboratory tasks, but less so in real-world studies (Hyland, 2011b; Lewith, Hyland, \& Shaw, 2002; Walach et al., 1997). Here, participants were offered a health-promoting exercise in study 1 and a gratitude therapy for smoking cessation in study 2 . These tasks are perhaps more representative of real-world therapeutic activities than the methods used in laboratory studies. The current findings further highlight that motivational factors may actually be more important than expectancies of benefit in real-world settings when people are motivated to improve their health.

Contrary to previous studies (e.g., Holden, 1992; Jackson, Tucker, Herman, 2007; Mosher et al, 2011), we did not find that self-efficacy was associated with engagement or adherence to health-related activities. This finding contrasts with Social Cognitive theory (Bandura, 1997), which predicts positive effects of self-efficacy on motivation (e.g. engagement) and behavior (e.g. adherence). Here, self-efficacy was measured at baseline prior to the delivery of health-related information about the activities. Perhaps self-efficacy would have been more relevant to engagement and adherence had it been measured following the provision of the health-related information. Future research should continue 
exploring the predictability value of self-efficacy when contrasted with other motivational constructs in similar health contexts.

Our results show that simple statements about the potential benefits of a health promoting activity can motivate engagement and adherence. However, this was only the case for study 2, which concerned a gratitude therapy for smoking cessation. One possible explanation is that participants in study 1 , who were offered a breathing exercise for improving well-being, did not have a good reason to engage in the treatment, or that the activity was not meaningful to them. For this reason, in study 2 , we targeted smokers with a desire to stop smoking, who presumably would be more invested in the potential outcomes of an activity designed for smoking cessation. Under these conditions, smokers who received the positive information about the therapy were more likely to adhere to the activity.

All health-promoting activities, including psychotherapies, are hypothetical until an individual actually engages with an activity. Our current findings speak to this stage of engagement, and go beyond a hypothetical stage by further showing that subsequent adherence after engagement can be predicted by motivational factors. These findings may have consequences for clinical practice. Intrinsic motivation emerged as a major predictor of both engagement and adherence. Health care professionals may seek to assign patients to therapies according to their level of intrinsic motivation (Houston et al., 2012). Attrition rates may be highest among individuals who are low in intrinsic motivation especially if assigned to demanding therapies. A simple measure of intrinsic motivation to be used in clinical practice may thus be effective in reducing attrition rates that result from low intrinsic motivation.

One limitation of our studies is that we provided an extrinsic reward for participants' participation. In principle, this could have influenced their motivation to participate in the 
study as well as their adherence to the health-promoting activities. However, despite this, individuals who were higher in intrinsic motivation nevertheless were more likely to engage with the activities and to adhere to them. A second limitation is that we recruited participants from the general public, rather than use a clinical sample. However, the exploratory nature of the present study provides the opportunity to test the present assumptions with clinical samples in the future.

In conclusion, in the two current real life health-promoting activity studies, being intrinsically motivated to perform a task was more important than expecting it to be beneficial. This finding has implications for clinical practice. Health care professionals should be cognizant that low intrinsic motivation to perform a therapeutic task is related to a greater likelihood of attrition. The delivery of simple statements about the potential benefits of a health promoting activity is one method of enhancing motivation and improving adherence.

\section{References}

Bandura, A. (1997). Self-efficacy: the exercise of control. New York, NY: Freeman.

Berinsky, A.J., Huber, G.A., Lenz, G.S., 2012. Evaluating online labor markets for experimental research: Amazon.com's mechanical turk. Political Analysis, 20, 351-368.

Bruton, A., \& Lewith, G.T. (2005). The Buteyko breathing method for asthma: A review. Complementary Therapies in Medicine, 13, 41-46.

Chiesa, A., Brambilla, P., \& Serreti, A. Functional neural correlates of mindfulness meditations in comparison with psychotherapy, pharmacotherapy and placebo effect. Is there a link? Acta Neuropsychiatrica, 22, 104-117 
Crum, A. J., \& Langer, E. J. (2007). Mind-set matters. Exercise and the placebo effect. Psychological Science, 18, 165-171.

Gaitan-Sierra, C., \& Hyland, M.E. (2011) Non-specific mechanisms that enhance well-being in health promoting behaviors. Health Psychology, 30, 793-796.

Gaitan-Sierra, C., \& Hyland, M.E. (2013). Mood enhancement in health-promoting non-aerobic exercise: The role of non-specific mechanisms. Journal of Health Psychology, 19. 918-930.

Gaitan-Sierra, C., \& Hyland, M.E. (2014). Common factor mechanisms in clinical practice and their relationship with outcome. Clinical Psychology \& Psychotherapy, 16. doi: 10.1002/cpp.1894.

Gallagher, K. M., \& Updegraff, J. A. (2012). Health message framing effects on attitudes, intentions, and behavior: A meta-analytic review. Annals of Behavioral Medicine, 43, 101116.

Holden, G. (1992). The Relationship of self-efficacy appraisals to subsequent health related outcomes: A meta-Analysis. Social Work in Health Care, 16, 53-93.

Houston, E., McKirnan, D.J., Cervone, D., Johnson, M.S., \& Sandfort, T.G. (2012). Assessing treatment motivation among patients receiving antiretroviral therapy: A multidimensional approach. Psychology \& Health, 27, 674-687

Hyland, M.E. (2011a). Motivation and placebos: Do different mechanisms occur in different contexts? Philosophical Transactions of the Royal Society B, 366: 1828-1837.

Hyland, M.E. (2011b). The Origins of Health and Disease. Cambridge: Cambridge University Press.

Hyland, M.E., Whalley, B., \& Geraghty, A. (2007) Dispositional predictors of placebo responding: A motivational interpretation of flower essence and gratitude therapy. Journal of Psychosomatic Research, 62, 331-340. 
Hyland, M.E., \& Whalley, B. (2008) Motivational concordance: An important mechanism in selfhelp therapeutic rituals involving inert (placebo) substances. Journal of Psychosomatic Research, 65, 405-413.

Jackson, E. S., Tucker, C. M., \& Herman, K. C. (2007). Health Value, Perceived Social Support, and Health Self-Efficacy as Factors in a Health-Promoting Lifestyle. Journal of American College Health, 56, 69-74.

Kirsch, I. (1985). Response expectancy as a determinant of experience and behavior. American Psychologist, 40, 1189-1202.

Kirsch, I. (1999). How expectancies shape experience. Washington, DC: American Psychological Association.

Kreuter, M. W., \& Wray, R. J. (2003). Tailored and targeted health communication: Strategies for enhancing information relevance. American Journal of Health Behavior, 27(Suppl.3), S227S232.

Lewith, G. T., Hyland, M. E., \& Shaw, S. (2002). Do attitudes and beliefs about complementary medicine affect treatment outcome? American Journal of Public Health, 92, 8-10.

Martin, L.R., \& DiMatteo, M.R. (Eds.). (2014). The Oxford handbook of health communication, behavior change, and treatment adherence. New York, NY: Oxford University Press.

McCullough, M. E., Emmons, R. A., \& Tsang, J. (2002). The grateful disposition: A conceptual and empirical topography. Journal of Personality and Social Psychology, 82, 112- 127.

Moerman, D. E., \& Jonas, W. B. (2002). Deconstructing the placebo effect and finding the meaning response. Annals of Internal Medicine, 136, 471-476.

Mosher, C.E., Lipkus, I., Sloane, R., et al. (2013) Long-term outcomes of the FRESH START trial: Exploring the role of self- efficacy in cancer survivors' maintenance of dietary practices and physical activity. Psycho-Oncology, 22, 876-885.

Novozhilov, A. (2004). Living without asthma: The Buteyko method. Postdam: Mobiwell Verlag. 
Thomas, M. (2003). Breathing methods and asthma. Thorax, 58, 649-650.

Paolacci, G., Chandler, J., \& Ipeirotis, P. G. (2010). Running experiments on Amazon Mechanical Turk. Judgment and Decision Making, 5, 411-419.

Pretty, J., Peacock, J., Sellens, M., \& Griffin, M. (2005). The mental and physical health outcomes of green exercise. International Journal of Environmental Health Research, 15, 319 -337.

Rothman, A.J., \& Salovey, P. (1997). Shaping perceptions to motivate healthy behavior: The role of message framing. Psychological Bulletin, 121, 3-19.

Spek, V., Lemmens, F., Chatrou, M., van Kempen, S., Pouwer, F., \& Pop, V. (2013).

Development of a smoking abstinence self-efficacy questionnaire. International Journal of Behavioral Medicine, 20, 444-449.

Van't Riet, J., Ruiter, R. A. C., Werrij, M. Q., \& De Vries, H. (2008). The influence of selfefficacy on the effects of framed health messages. European Journal of Social Psychology, 38, 800-809.

Van’t Riet, J., Ruiter, R. A. C., Werrij, M. Q., \& De Vries, H. (2010). Self-efficacy moderates message-framing effects: The case of skin-cancer detection. Psychology \& Health, 25, 339349.

Walach, H., Gaus, W., Haeusler, W., Lowes, T., Mussbach, D., \& Schamell, U. (1997). Classical homoeopathic treatment of chronic headaches: A double-blind, randomized, placebocontrolled study. Cephalalgia, 17, 119-126

Wood, A. M., Froh, J. J., \& Geraghty, A. W. (2010). Gratitude and well-being: A review and theoretical integration. Clinical Psychology Review, 30, 890-905. 
Table 1

Descriptions of the Breathing Method Provided to Participants in the Vignettes

'Known effectiveness' description

'Unknown effectiveness' description 
The Lacastre breathing method works as follows. A high breathing rate, causes a decrease in oxygen in the blood. This has a wide range of effects, including respiratory complaints and mood disturbances. A conscious reduction in breathing rate and a decrease in deep breathing can help reestablish normal carbon dioxide levels by retraining normal breathing. The evidence is that asthma symptoms and medication use are reduced by the Lacastre breathing method for asthma patients and that this leads to improvements in quality of life. For healthy individuals, practicing the Lacastre method reduces risk of health problems associated with improper breathing and improves mood and psychological wellbeing.

The Lacastre method is based on a series of breathing activities designed to reduce breathing rate. The methods stress the importance of breathing through the nose, rather than the mouth. By doing so, the tendency to breathe quickly is reduced and the nose breathing oxygenates the blood with positive health outcomes. Previous studies demonstrating the positive effects of the Lacastre method have been conducted in treatment centers and in research laboratories. The purpose of this study is to explore the positive effects of the method on mood and well-being using a set of methods that can be completed independently in the home.
The Lacastre breathing method is thought to work as follows. A high breathing rate causes a decrease in oxygen in the blood. This has a wide range of effects, including respiratory complaints and mood disturbances. A conscious reduction in breathing rate and a decrease in deep breathing can help re-establish normal carbon dioxide levels by retraining normal breathing. The Lacastre method is currently in the early stages of testing. It is proposed that asthma symptoms and medication use will be reduced by the Lacastre breathing method for asthma patients and that this will lead to improvements in quality of life. For healthy individuals, it is proposed that practicing the Lacastre method will reduce risk of health problems associated with improper breathing and will improve mood and psychological well-being, but whether this is true, we really don't know.

The Lacastre method is based on a series of breathing activities designed to reduce breathing rate. The methods stress the importance of breathing through the nose, rather than the mouth. By doing so, the tendency to breathe quickly is expected to reduce and the nose breathing is expected to oxygenate the blood with positive health outcomes. Other studies are testing the effects of the Lacastre method in treatment centers and in research laboratories. The purpose of this study is to explore whether the method has effects on mood and wellbeing using a set of methods that can be completed independently in the home.

Table 2

Demographic Characteristics of Participants: Study 1

$\begin{array}{cc}\text { Stage 1 } & \text { Stage 2 } \\ \mathrm{N}=121 & \mathrm{~N}=53\end{array}$




\begin{tabular}{|c|c|c|}
\hline \multicolumn{3}{|l|}{ Gender $(\%)$} \\
\hline Females & $53(43.80)$ & $26(49.10)$ \\
\hline Males & $68(56.20)$ & $27(50.90)$ \\
\hline \multicolumn{3}{|l|}{ Age } \\
\hline Mean $(S D)$ & $34.18(10.81)$ & $35.22(10.94)$ \\
\hline Range & $19-67$ & $21-62$ \\
\hline \multicolumn{3}{|l|}{ Education $(\%)$} \\
\hline$<$ High school & 0 & 0 \\
\hline High school graduate & $53(43.80)$ & $15(28.30)$ \\
\hline College graduate or university graduate & $59(48.80)$ & $35(66.00)$ \\
\hline Post graduate education & $9(7.40)$ & $3(5.70)$ \\
\hline \multicolumn{3}{|l|}{ Income $(\%)$} \\
\hline$<\$ 10,000$ & $9(7.40)$ & $5(9.40)$ \\
\hline$\$ 10-20,000$ & $20(16.50)$ & $8(15.10)$ \\
\hline$\$ 21-30,000$ & $35(29.00)$ & $17(32.10)$ \\
\hline$\$ 31-40,000$ & $36(29.80)$ & $13(24.60)$ \\
\hline$\$ 41,-50,000$ & $8(6.60)$ & $6(11.30)$ \\
\hline$\$ 51>$ & $13(10.70)$ & $4(7.50)$ \\
\hline \multicolumn{3}{|l|}{ Employment (\%) } \\
\hline Full-time employed & $64(52.90)$ & $28(52.80)$ \\
\hline Part-time employed & $25(20.70)$ & $12(22.60)$ \\
\hline Unemployed & $13(10.70)$ & $6(11.30)$ \\
\hline Retired & $2(1.70)$ & $1(1.90)$ \\
\hline Student & $11(9.10)$ & $2(3.80)$ \\
\hline Housewife & $6(5.00)$ & $4(7.50)$ \\
\hline
\end{tabular}

Note. Stage 1 refers to all participants who completed the Stage 1 questionnaire. Stage 2 refers to participants who chose to complete Stage 2 and who completed the follow-up questionnaire at Stage 2.

Table 3

Logistic Regression Analyses on Engagement and Adherence to the Breathing Method 


\begin{tabular}{|c|c|c|c|c|c|c|}
\hline \multirow[b]{2}{*}{ Predictor variables } & \multirow[b]{2}{*}{ Odds ratio } & \multicolumn{2}{|c|}{$\begin{array}{c}95 \% \text { CI for Odds } \\
\text { ratio }\end{array}$} & \multirow[b]{2}{*}{ Odds ratio } & \multicolumn{2}{|c|}{$\begin{array}{c}95 \% \text { CI for Odds } \\
\text { ratio }\end{array}$} \\
\hline & & Lower & Upper & & Lower & Upper \\
\hline $\begin{array}{l}\text { Known vs. unknown } \\
\text { effectiveness }\end{array}$ & 1.426 & 0.641 & 3.148 & 1.351 & 0.364 & 5.011 \\
\hline Intrinsic motivation & $1.170 *$ & 1.031 & 1.329 & $1.175^{*}$ & 1.020 & 1.354 \\
\hline Expectancy & 0.787 & 0.512 & 1.209 & 1.927 & 0.865 & 4.292 \\
\hline Self-efficacy & 0.969 & 1.001 & 0.928 & 1.014 & 0.909 & 1.131 \\
\hline
\end{tabular}

$* p<.05$

Table 4

Descriptions of the Gratitude Therapy Provided to Participants in the Vignettes

"Known effectiveness" vignette

"Unknown effectiveness" vignette

Gratitude is an emotion expressing

Gratitude is an emotion expressing 
appreciation for what one has (e.g., family, friends, and health). It also describes a general feeling of thankfulness for life itself or for good aspects of life. Gratitude therapy cultivates feelings of gratitude through the regular practice of positive thinking about aspects of one's life.

Gratitude therapy is a particular way of helping people to increase their well-being. Several published studies in respected scientific journals have shown that gratitude therapy benefits the immune system, health, and mood, and is effective in the treatment of psychological conditions. One such benefit of gratitude therapy has been to help people stop smoking.

Gratitude therapy is particularly useful for people who wish to stop smoking but who may have failed to stop by other methods. In gratitude therapy, the person completes a gratitude diary, in which they enter the things in their life that they are grateful for (e.g., I'm thankful for the desire to quit). appreciation for what one has (e.g., family, friends and health). It also describes a general feeling of thankfulness for life itself or for good aspects of life. Gratitude interventions have been developed, in the belief that it is beneficial to help people focus on the positive aspects of life.

There is very little research conducted on gratitude interventions and there is no general consensus that gratitude interventions may be related to better health or that they have any other positive benefits.

No studies have examined the effects of a gratitude intervention on helping people to stop smoking, but we want to work out whether or not a gratitude intervention is useful for this behavior. We have developed a gratitude method but we do not know whether it works or not.

The gratitude method consists of completing a gratitude diary. It involves writing down things in your life you are grateful for. For example, being thankful for the desire to quit.

Table 5

Demographic Characteristics of Participants: Study 2 


\begin{tabular}{|c|c|c|}
\hline & $\begin{array}{l}\text { Stage 1 } \\
\mathrm{N}=121\end{array}$ & $\begin{array}{l}\text { Stage } 2 \\
\quad \mathrm{~N}=50\end{array}$ \\
\hline \multicolumn{3}{|l|}{ Gender $(\%)$} \\
\hline Females & $59(48.80)$ & $27(54.00)$ \\
\hline Males & $62(51.20)$ & $23(46.00)$ \\
\hline \multicolumn{3}{|l|}{ Age } \\
\hline Mean $(S D)$ & $36.11(12.14)$ & $38.28(13.49)$ \\
\hline Range & $19-75$ & $19-75$ \\
\hline \multicolumn{3}{|l|}{ Education $(\%)$} \\
\hline$<$ High school & $2(1.70)$ & $1(2.00)$ \\
\hline High school graduate & $47(38.80)$ & $21(42.00)$ \\
\hline College graduate or university graduate & $65(53.70)$ & $26(52.00)$ \\
\hline Post graduate education & $7(5.80)$ & $2(4.00)$ \\
\hline \multicolumn{3}{|l|}{ Income $(\%)$} \\
\hline$<\$ 10,000$ & $10(8.30)$ & $3(6.00)$ \\
\hline$\$ 10-20,000$ & $21(17.40)$ & $9(18.00)$ \\
\hline$\$ 21-30,000$ & $21(17.40)$ & $10(20.00)$ \\
\hline$\$ 31-40,000$ & $42(34.65)$ & $10(20.00)$ \\
\hline$\$ 41,-50,000$ & $14(11.55)$ & $7(14.00)$ \\
\hline$\$ 51>$ & $13(10.70)$ & $11(22.00)$ \\
\hline \multicolumn{3}{|l|}{ Employment (\%) } \\
\hline Full-time employed & $73(60.30)$ & $27(54.00)$ \\
\hline Part-time employed & $17(14.00)$ & $10(20.00)$ \\
\hline Unemployed & $12(9.90)$ & $5(10.00)$ \\
\hline Retired & $10(8.30)$ & $5(10.00)$ \\
\hline Student & $5(4.10)$ & $2(4.00)$ \\
\hline Housewife & $4(3.30)$ & $1(2.00)$ \\
\hline
\end{tabular}

Table 6 


\begin{tabular}{|c|c|c|c|c|c|c|}
\hline \multirow[b]{3}{*}{ Predictor variables } & \multicolumn{3}{|c|}{ Engagement } & \multicolumn{3}{|c|}{ Adherence } \\
\hline & \multirow[b]{2}{*}{ Odds ratio } & \multicolumn{2}{|c|}{$\begin{array}{l}95 \% \text { CI for } \\
\text { Odds ratio }\end{array}$} & \multirow[b]{2}{*}{ Odds ratio } & \multicolumn{2}{|c|}{$\begin{array}{l}95 \% \text { CI for } \\
\text { Odds ratio }\end{array}$} \\
\hline & & Lower & Upper & & Lower & Upper \\
\hline $\begin{array}{l}\text { Known vs. Unknown } \\
\text { effectiveness }\end{array}$ & 1.468 & .631 & 3.417 & $.107 * *$ & .023 & .499 \\
\hline Intrinsic motivation & $1.210 * *$ & 1.070 & 1.369 & $1.278 *$ & .993 & 1.644 \\
\hline Expectancy & .910 & .606 & 1.365 & .812 & .391 & 1.690 \\
\hline Self-efficacy & .983 & .901 & 1.071 & .972 & .847 & 1.115 \\
\hline $\begin{array}{l}\text { Willingness to stop } \\
\text { smoking }\end{array}$ & 1.011 & .992 & 1.030 & 1.025 & .983 & 1.070 \\
\hline
\end{tabular}

${ }^{*} p<.05, * * p<.01$ 